Nuria Lázaro Milla

Doctora en Historia del Arte

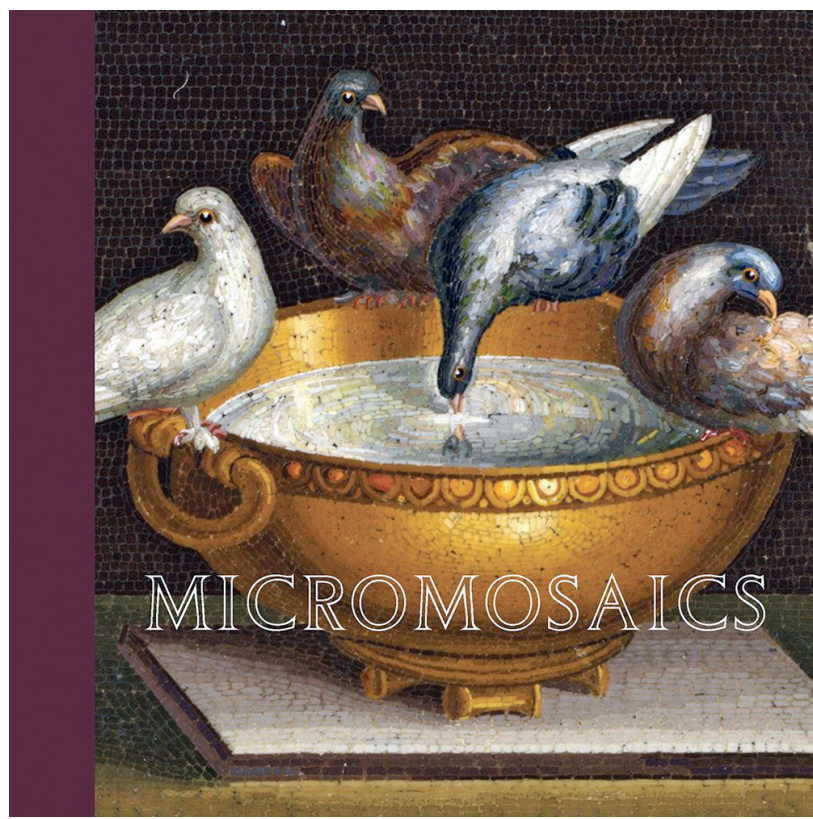

\title{
Micromosaics. Masterpieces from the Rosalinde and Arthur Gilbert collection Heike Zech
}

Londres, V\&A Publishing, 2018

144 págs

ISBN: 978-1-85177-970-3

El matrimonio formado por Rosalinde (1913-1995) y Arthur Gilbert (1913-2001) reunió una de las más importantes colecciones de artes decorativas de su generación. En concreto, focalizaron su atención en cajas de oro, objetos religiosos y civiles de oro y plata, retratos esmaltados en miniatura, trabajos en piedras duras y micromosaicos; término cuya acuñación se atribuye, precisamente, al señor Gilbert. En la década de 1970, parte de dicha colección se cedió para ser expuesta en el Museo de Arte del Condado de Los Ángeles y en 1996, el resto fue donado a Reino Unido, su nación de origen, conservándose desde 2008 en el Museo Victoria y Alberto de Londres.

Los micromosaicos, esto es, mosaicos compuestos por teselas diminutas, comenzaron a realizarse en Roma, en el seno del Estudio del Mosaico del Vaticano, a partir de la segunda mitad del siglo XVIII, gozando de gran acogida en la centuria siguiente y hasta el inicio del siglo XX. Entre los factores que contribuyeron a su éxito se hallan la cultura neoclásica, que asimiló la técnica y algunos de los temas a la Antigüedad latina, y el fenómeno del Grand Tour, pues su pequeño tamaño favoreció que fueran comprados como recuerdos. Las memorias de viajeros constatan que ya a principios del siglo XIX existían en Roma cientos de artistas dedicados a esta labor, muchos de ellos produciendo de manera seriada, con la consecuente pérdida de calidad. También se inauguraron escuelas en París y San Petersburgo que seguían el modelo del Estudio Vaticano, pero su trayectoria fue fugaz.

Las teselas, de pasta vítrea de color opaco, se adherían a una base de metal, piedra o vidrio. Cuando la masilla secaba, los huecos se rellenaban con cera y se pulimentaba la superficie. A continuación, las placas se enmarcaban y dejaban exentas o se acoplaban como ornamentación en joyas, complementos de moda, tableros de mesa, objetos de vitrina o artículos de escritorio. En los micromosaicos, como en toda manifestación artística, se observa una evolución; en este caso, desde el temprano uso de teselas cuadrangulares ordenadas en filas hasta el posterior empleo de teselas de formas y colores diversos, colocadas de tal modo que aportan volumen y perspectiva.

Tras esta interesante introducción histórica, técnica y estilística, Heike Zech (antigua conservadora de la colección Gilbert del Museo Victoria y Alberto) pasa a realizar un catálogo razonado de las cincuenta piezas de micromosaico más importantes que integran la misma.

La relación, magníficamente ilustrada, está ordenada atendiendo a los muy diferentes asuntos tratados en micromosaico. Las vistas de Roma y sus alrededores fueron, sin lugar a duda, emblemáticas, plasmándose tanto ruinas antiguas como construcciones modernas que han convertido a la ciudad en eterna. Igualmente, fueron protagonistas idílicos paisajes, caracterizados por frondosas vegetaciones y sugerentes caídas de agua, que evocan los pintados en el siglo XVII por Nicolás Poussin y Claudio de Lorena. Las flores, como fragmentos domésticos de esa naturaleza, también tuvieron presencia, organizadas en exuberantes y coloridos ramos, cestos o festones que recuerdan a los inmortalizados por los bodegones flamencos. En cuanto al mundo animal, sobresalieron las mariposas (como símbolo griego del alma); las aves (principalmente 
gallinas y gallos, y, sobre todo, palomas por influencia del mosaico con ese sujeto originario de la Villa Adriana); los perros (con preferencia, curiosamente, por las razas spaniel y caniche) y fieras variopintas (a menudo en actitud de caza o lucha). Los personajes mitológicos, religiosos e históricos fueron muy habituales, así como las representaciones de aldeanos, ataviados con trajes regionales pero envueltos en una atmósfera bucólica. Los motivos de inspiración grecolatina, bizantina e incluso, egipcia, vincularon los micromosaicos con las tendencias historicistas, tan en boga en la época. Por último, han de citarse las reproducciones de obras artísticas de los maestros más eminentes, cuyo antecedente ha de buscarse en la tarea que el propio Estudio del Mosaico del Vaticano inició en el siglo XVIII, consistente en la sustitución de las pinturas de gran formato de la Basílica de San Pedro por copias en mosaico para preservarlas de las condiciones ambientales adversas.

Conviene señalar que, en un arte mayoritariamente anónimo, el catálogo aporta nombres y datos sobre mosaiquistas, algunos de ellos entre los más afamados, como Giacomo Raffaelli, Antonio Aguatti, Michelangelo Barberi, Filippo Puglieschi, Francesco Belloni, Clemente Ciuli o Luigi Moglia.

Además de bibliografía de referencia, la autora añade al final un glosario que facilita la comprensión de los términos más específicos.

El libro es el resultado de una ardua tarea de revisión, actualización y síntesis de la bibliografía precedente sobre los mismos fondos, y viene a confirmar cómo por la cantidad, variedad, calidad y riqueza de las piezas, la colección Gilbert de micromosaicos es una de las más importantes a nivel internacional. Micromosaics. Masterpieces from the Rosalinde and Arthur Gilbert collection, por Heike Zech, es, en definitiva, un excelente punto de partida para quien desee iniciarse en el estudio de los micromosaicos. 